\title{
A EVOLUÇÃO DOS CONFLITOS ARMADOS NO ORDENAMENTO JURÍDICO INTERNACIONAL: um estudo sobre a guerra no Sudão do Sul
}

\author{
Josias Marcos de Resende Silva \\ Leticia Mirelli Faleiro e Silva
}

\section{RESUMO}

No presente artigo, serão apresentadas as espécies de conflitos existentes no direito internacional. Em sequência, será analisado o conflito no Sudão do Sul. Ao final deste trabalho, será verificada a contribuição das partes envolvidas no conflito, dos atores externos e do sistema econômico internacional para essa guerra. A vertente metodológica adotada foi a jurídico-teórica, o tipo de raciocínio foi o dedutivo. Os tipos metodológicos utilizados na pesquisa foram histórico-jurídico, jurídico-comparativo e jurídico-interpretativo. Concluiu-se que a guerra no Sudão do Sul pode ser considerada um conflito internacionalizado, com um significativo viés econômico e uma relevante influência de atores internacionais.

Palavras-chave: Guerra Civil; Conflito Interno; Conflito Internacionalizado; Globalização; Sudão do Sul.

\section{THE EVOLUTION OF ARMED CONFLICTS IN THE INTERNATIONAL LEGAL ORDINANCE: a study on the War in South Sudan}

\begin{abstract}
This article will examine the existing types of conflicts within the international law. Then, the conflict in South Sudan will be analyzed. In the end, this paper will verify the contributions of the parties to the conflict, external actors, and the international economic system to this war. The methodological approach was the legal-theoretical and the scientific process was the deductive reasoning. The methodological types of this research were historical-legal comparative-legal and legal interpretative. As a conclusion, the war in South Sudan can be considered an internationalized conflict, with a significant economic side and a relevant influence of international actors.
\end{abstract}

Keywords: Civil War; Internal Conflict; Internationalized Conflict; Globalization; South Sudan.

\section{Introdução}


Desde os primórdios da civilização, o homem se via obrigado a lutar para se defender dos perigos, até mesmo como forma de subsistência, porém essa luta tinha caráter pessoal. Diante do desenvolvimento da sociedade, surgem os agrupamentos humanos e o viés individual das disputas cede lugar aos conflitos coletivos. Uma ofensa a determinado membro do grupo passou a afetar aos demais, o que começou a ser reprimido, por sua vez, de maneira coletiva (MAZZUOLI, 2016, p. 1.188).

Em um novo contexto onde a sociedade assume um papel organizado, as divergências se tornam incômodas, sobretudo pela diferença no modo de pensar de cada indivíduo, o que vem a ser majorado frente aos interesses humanos diversos, padecendo, portanto, de resolução. Decorrem daí disputas e conflitos, o que se apresenta como algo praticamente inevitável.

É assim que, juntamente com o surgimento dos Estados, no século XVI, nascem também as controvérsias, agora de maneira mais estruturada. As guerras, as quais eram vistas como algo bastante natural, foi o meio mais utilizado para solucionar as controvérsias até o século XX (JUBILUT, 2007, p. 140).

Neste cenário surge o Direito Internacional, que a priori se voltava quase que exclusivamente para as questões relacionadas à guerra. Somente após as duas grandes guerras mundiais é que a preocupação com a paz passa a se sobrepor à guerra, a qual a partir de então deixa de ser a regra a ser utilizada na solução de uma controvérsia, cedendo lugar aos meios pacíficos.

É então que a guerra passa a ser vista com maus olhos, é reconhecida como um assassinato em massa, como a maior desgraça de nossa cultura, sendo que a principal tarefa política é garantir a paz mundial, que se apresenta muito mais importante do que decidir entre democracia e autocracia, capitalismo e socialismo (KELSEN,2010, p. XXII).

Ainda que se reconheça grande progresso decorrente da utilização da guerra apenas em casos excepcionais, com a consequente priorização das soluções pacíficas, onde a paz passa a ser algo desejado pela nação, surgem novos conflitos, os quais assumem uma nova aparência. Estes novos conflitos deixam de ser algo exclusivamente internacional, travados entre Estados soberanos, e passam a ostentar um cunho interno, travados dentro do próprio Estado. Dessa forma, eles foram batizados de conflitos internos, guerras civis, conflitos internacionalizados ou híbridos.

Com essa roupagem é que há aproximadamente cinco anos se desenvolveu o conflito interno no Sudão do Sul. Apoiado por potências ocidentais, em especial os Estados Unidos da 
América (EUA), no ano de 2011 o país obteve sua independência, após séculos de colonização e submissão. No entanto, após apenas dois anos de relativa paz, que perdurou entre2011 e 2013, o mais jovem Estado soberano do mundo tornou-se palco de uma violenta guerra civil, acompanhada por uma crise humanitária sem precedentes.

O conflito sul-sudanês tem sido travado entre grupos rivais históricos, que se uniram no passado em prol de obter a emancipação do país. A partir de 2013, a frágil estrutura estatal recém-criada entrou em colapso, lançando esses grupos em uma luta armada pelo poder. Nessa conjuntura complexa, rivalidades históricas, diferenças étnicas, má governança e interesses externos apresentaram-se como fatores que contribuíram para a continuação da guerra civil. Entretanto, a disputa pelo controle da produção de petróleo, principal fonte de receita do país, tanto por grupos internos como por atores internacionais, possui grande relevância para as partes envolvidas.

Diante deste contexto, a presente pesquisa pretende investigar se o sistema econômico internacional contribuiu de maneira significativa para a deflagração e continuação do conflito no Sudão do Sul.

Para desenvolvimento da presente pesquisa, adotar-se-á a vertente metodológica jurídico-teórica, uma vez que se destacará aspectos doutrinários e históricos. O tipo de raciocínio utilizado será o dedutivo. Os tipos metodológicos da pesquisa serão o históricojurídico, jurídico-comparativo e jurídico-interpretativo.

\section{Contexto histórico da Guerra: gênese do conflito internacional}

As guerras como sendo o uso da força utilizada para colocar fim a uma disputa eram exercidas há mais de mil anos antes de Cristo e, quando se fala em batalhas marcantes da antiguidade, rememoramos a Guerra de Tróia, a qual ocorreu aproximadamente entre os anos 1300a.Ce 1200 a.C. Como se sabe, esse conflito iniciou por uma razão bem diversa de todas as outras razões suscitadas nas demais disputas subsequentes. De maneira singular, o que deu motivo à essa guerra, segundo a mitologia grega, foi o rapto da rainha Helena de Esparta pelo filho do rei de Tróia, que por ela havia se apaixonado.

Indo mais adiante, as guerras surgiram por outros tantos propósitos. Ainda na Grécia antiga, elas eram fundadas na ideia de que a superioridade justificaria a luta, fato pelo qual através dela se buscava a excelência, tendo por finalidade o extermínio. Em Roma, em função do espírito imperialista daqueles povos, os conflitos eram guerras de anexação, fundadas em tratados e alianças entre os vencidos e vencedores. Na idade média, as guerras apresentavam 
cunho religioso prioritariamente, sobretudo em razão da não separação entre Estado e Igreja, além de visar uma homogeneidade religiosa. Na Idade Moderna, sobretudo após a Ordem Internacional de Vestfália, a guerra era decidida pelos Estados no exercício de sua soberania (JUBILUT, 2007, p. 141).

Como se pode observar, na antiguidade e idade média, as guerras eram provocadas especialmente por motivos étnicos e religiosos, ao passo que os conflitos em razão de interesses políticos e econômicos são mais recentes. Além disso, elas eram vistas como algo capaz de propiciar a evolução da humanidade, de medir poder, de modo que tanto a ascensão como a queda das civilizações estava intrinsecamente ligada à utilização da força de maneira acertada.

As inúmeras batalhas espalhadas por todo o globo terrestre ao longo dos séculos, desde aquelas da antiguidade, foram responsáveis por alterar a geografia do mundo, de modo que cidades foram dizimadas e outras foram anexadas, se tornando uma só. Além disso, elas foram capazes de promover o enriquecimento de muitos povos, mediante a derrota de outros, expandir territórios, enaltecer líderes, proclamar heróis e etc.

O que diferencia aquelas guerras das atuais é a forma como eram organizadas e, principalmente, a tecnologia utilizada no combate. Em um passado distante, os combatentes se valiam da infantaria, da falange, das bigas, arcos e lanças como ferramentas rudimentares de guerra. Por mais que todo combate tenha cunho eminentemente destrutivo, as primeiras guerras da história não foram capazes de causar danos tão significativos como aqueles decorrentes das duas grandes guerras mundiais e de outros tantos conflitos mais recentes.

É assim que, tantos séculos depois das grandes batalhas do passado, as guerras estão mais atuais do que nunca, pois, frente a evolução tecnológica crescente, elas se tornaram mais crueis, com efeito de destruição nunca antes visto.

\begin{abstract}
A análise histórica e o pensamento político permitem crer, embora de modo indefinido e genérico, que a estrutura essencial de toda a civilização atingiu o ponto de ruptura. Mesmo quando aparentemente melhor preservada, o que ocorre em certas partes do mundo, essa estrutura não autoriza antever a futura evolução do que resta do século XX, nem fornece explicações adequadas aos seus horrores. Incomensurável esperança, entremeada com indescritível temor, parece corresponder melhor a esses acontecimentos que o juízo equilibrado e o discernimento comedido. Mas os eventos fundamentais do nosso tempo preocupam do mesmo modo os que acreditam na ruína final e os que se entregam ao otimismo temerário. (ARENDT, 2012, p.12).
\end{abstract}

Diante do progresso desse instituto que com o passar dos tempos assumiu cunho técnico, a guerra passa assim a ser definida: 
A guerra pode ser conceituada como todo conflito armado entre dois ou mais Estados, durante um certo período de tempo e sob a direção dos seus respectivos governos, com a finalidade de forçar um dos adversários a satisfazer a(s) vontade(s) do(s) outro(s). Ela normalmente se inicia com uma declaração formal de guerra e termina com a conclusão de um Tratado de Paz, ou outro ato capaz de pôr termo às hostilidades e findá-la por completo. (MAZZUOLI, 2016, p. 1189).

\subsection{Causas da guerra: existência de uma controvérsia}

Diante das barbáries de uma guerra, é comum que os indivíduos naturalmente aterrorizados com todo sofrimento e derramamento de sangue decorrente de um conflito, o qual adentra as suas casas em tempo real através dos diversos meios de comunicação, queiram saber os motivos que levam seres humanos a travarem batalhas de maneira tão fria e cruel.

O senso comum diz que não há no mundo motivo que justifique a eclosão de uma guerra, ao passo que não é mais possível distinguir guerras justas de guerras injustas, pois todas as guerras são injustas. (BOBBIO, 2003).

No entanto, em sentido técnico-jurídico, há uma explicação plausível para se iniciar uma guerra, a qual advém de uma controvérsia não resolvida, ou seja, quando uma das partes tem uma pretensão e a outra parte resiste a ela, restando frustrada qualquer solução pacífica. Isso pode ocorrer entre dois ou mais Estados ou entre Organizações Internacionais, se fazendo necessário, portanto, o uso da força entre os envolvidos.

Em se tratando de controvérsia no seio de um Estado, ou seja, uma controvérsia de ordem interna, o que é bastante comum, essa questão é resolvida via de regra por meios brandos e pacíficos, uma vez que ali há uma autoridade hierarquicamente superior responsável por solucionar contendas domésticas, sobretudo por meios normativos.

Já na comunidade internacional inexiste a figura centralizada de um ente que seja superior e gestor de toda ordem, o que impossibilita a solução de uma controvérsia de maneira razoável, fato pelo qual o uso da força se torna "cogente". Neste sentido:

A ordem internacional, por ser descentralizada não apresenta essa hierarquia, o que
torna a solução de disputas em seu âmbito, diferenciada, especialmente porque os
litígios, em sua maioria, envolvem Estados soberanos, que por definição não se
submetem a nenhuma outra autoridade, daí por que, mesmo existindo instituições na
esfera internacional, elas não conseguem evitar o recurso à força. (JUBILUT, 2007,
p. 140).

É importante mencionar que as ditas controvérsias advêm de motivos múltiplos, entre eles os de caráter religioso, político, cultural e econômico. Há estudiosos do tema que ressaltam desconhecerem com profundidade as causas de uma guerra, emergindo daí, segundo afirmam, uma barreira para o encontro de uma solução: 
A verdade é que, não obstante as inúmeras pesquisas sobre a paz espalhadas pelas mais diversas partes do mundo, não sabemos nada ou quase nada das causas das guerras: econômicas, sociais, políticas, ideológicas, religiosas, nacionais e, como nestes últimos tempos, tribais e étnicas. Mas como se pode encontrar o remédio para um mal do qual não conhecemos a causa? (BOBBIO, 2003, p.17).

Durante muito tempo, a guerra era o único meio para se solucionar divergências existentes, de modo que a partir dela se proclamaria um vencedor, fato pelo qual, ao menos uma das partes divergentes teria ao final a "razão", o direito de ver respeitada a sua vontade, ainda que de maneira imposta.

A importância das guerras era tão significativa que a própria filosofia da história, a qual procede a uma reflexão contínua sobre o destino da humanidade, se ocupava em estudála. É assim que a guerra sempre foi um dos temas obrigatórios e prediletos de toda filosofia da história, pelas características de terribilidade ou de fatalidade que parecem ou quase sempre pareceram inerentes a ela (BOBBIO, 2003, p.51). Sobre o tema:

Se a filosofia da história é a reflexão sobre o destino da humanidade no seu conjunto, a presença da guerra em cada fase da história humana, pelo menos até hoje, constitui para essa reflexão um dos problemas mais inquietantes e fascinantes. Aliás, como já se notou várias vezes, o lugar de origem e de crescimento das filosofias da história são as grandes catástrofes da humanidade, e entre estas a guerra ocupa um lugar proeminente". (BOBBIO, 2003, p.51/52).

No entanto, diante dos efeitos avassaladores das duas grandes Guerras Mundiais, e consequentemente com o surgimento dos Direitos Humanos no Estado, o direito internacional passa a clamar por soluções pacíficas de controvérsias de modo a atenuar e evitar a banalização dos conflitos armados no direito das gentes. É dentro deste contexto que erige na comunidade internacional a preocupação pela paz no mundo. Neste sentido:

Durante muito tempo a tônica das relações internacionais foi a guerra, razão pela qual o Direito Internacional preocupou-se na maior parte de sua existência, com este fenômeno. A preocupação com a paz é algo recente na história, surgindo mais especificamente no século XX”. (JUBILUT, 2007, p. 139).

Porém, muito antes, Kant já expressava em sua obra "A Paz Perpétua”, os anseios do filósofo pela prevalência de uma paz constante, "deixe-se de lado se esta inscrição satírica na tabuleta de uma estalagem holandesa, em que estava pintando um cemitério, vale para os homens em geral, ou em particular para os chefes de Estado, que nunca estão fartos de guerra, ou quiçá somente para os filósofos que sonham com este doce sonho.” (KANT, 2017, p.13).

Diante do novo cenário, o Direito Internacional por meio da Carta das Nações Unidas passa a considerar a guerra como um meio ilícito para a solução de controvérsias internacionais e, é nesse ponto, que ela deixa de ser o melhor meio para a solução de controvérsias, sendo então substituída pelos meios pacíficos. 


\subsection{A ilicitude da guerra e os meios pacíficos para solução de um conflito}

$\mathrm{O}$ viés jurídico da guerra nasce apenas no século $\mathrm{XX}$, quando o Pacto da Liga das Nações estabelece a proibição da guerra entre os Estados membros, o que foi reforçado em agosto de 1928 pela assinatura do Tratado de Renúncia a Guerra, conhecido como Pacto Briand-Kellog, e pela Carta das Nações Unidas, a qual proíbe formalmente a guerra, a considerando um ilícito internacional. É assim que ela deixa de ser um direito do Estado, o qual não pode mais atuar em busca unicamente da satisfação de suas vontades.

Porém, antes mesmo de a guerra ter se tornado juridicamente ilícita por meio da Carta das Nações Unidas de 1945, o direito internacional, ainda que de maneira incipiente, caminhava rumo a esse propósito. De fato, foi publicada no ano de 1907 a Convenção Drago Porter, também conhecida como $2^{\mathrm{a}}$ Convenção de Haia, que iniciou esta caminhada banindo o uso da força para cobrança de dívidas.

Há a partir daí a limitação do uso da força. Tendo sido um começo tênue, a referida medida não foi capaz de impedir a eclosão da Primeira Guerra Mundial nos anos de 1914 a 1918, fato pelo qual foi criada, ao término deste combate, a Liga das Nações, que tinha como propósito primordial evitar tragédia semelhante.

Nesse ínterim, foi editado o Pacto da Liga das Nações, posteriormente incorporado ao primeiro tratado de paz, denominado Tratado de Versalhes de 1919, no qual a guerra passa a ser secundária pela primeira vez na história, apesar de não ter sido abolida formalmente.

Porém, conforme preleciona Jubilut, o Pacto da Liga das Nações não foi suficiente para vedar a guerra e, por esta razão, em um patente progresso foi criado no ano de 1928 o Pacto Briand-Kellog, ou Tratado de Paris (JUBILUT, 2007, p.142) como também é conhecido. A guerra, aqui, já não era alternativa a ser evitada, pois os Estados pactuantes a condenam e a ela renunciam (REZEK, 2000, p.363), podendo excepcionalmente ocorrer somente nos casos de legítima defesa.

Por mais que esse instrumento tenha representado um avanço normativo significativo, ainda não havia sido capaz de por si só funcionar na prática, exatamente em decorrência da inexistência de mecanismos capazes de torná-lo efetivo. É nesse sentido que Kelsen preleciona:

O insucesso do pacto Kellog-Briand, entretanto, deve-se a sua própria insuficiência técnica. Por um lado, o pacto almejou demais, proibindo qualquer tipo de guerra, mesmo a guerra contra a violação do direito, sem substituir essa sanção do direito internacional por outro tipo, uma sanção organizada em âmbito internacional. Desse modo, favoreceu os Estados inclinados a violar os direitos dos outros Estados. Por 
outro lado, esse pacto assumiu responsabilidades de menos, obrigando os Estados a procurar a solução pacífica de suas disputas sem obrigá-los a apresentar todos os seus conflitos, sem exceção, à jurisdição compulsória de um tribunal internacional (KELSEN, 2010, p. 17).

Então, alguns anos depois houve a eclosão da Segunda Guerra Mundial. Diante das atrocidades vivenciadas nesta guerra, a preocupação da comunidade internacional com a segurança e a paz internacionais atingiu o seu ápice de modo que os Estados, como um todo, se inseriram em um cenário de cooperativismo em face da criação da Organização das Nações Unidas.

É assim que a ONU, robustecendo aquilo que foi embrionariamente previsto no Pacto de Paris, veda novamente a guerra, a qual é autorizada apenas e tão somente em três casos, notadamente, as guerras de legítima defesa, as operações para manutenção da paz e ações contra Estados considerados inimigos à época da Segunda Guerra Mundial. Extrai-se daí que são permitidas apenas guerras "defensivas", e ainda assim é imprescindível que as mesmas sejam previamente aprovadas pela comunidade internacional, por meio do Conselho de Segurança da ONU. Segundo Mazzuoli:

\begin{abstract}
A guerra só será permitida em caso de legítima defesa dos seus direitos, comprovada por uma agressão injusta ou por um perigo de dano atual e iminente. Porém, mesmo sendo reconhecida como um ilícito, ela não deixou de existir, sobretudo no aspecto regional, o que demonstra que mesmo que tenha sido juridicamente proibida, o direito internacional não foi ainda capaz de obrigar as grandes potências mundiais a respeitar as normas que tornem a guerra menos destrutiva. (MAZZUOLI, 2017).
\end{abstract}

Apesar desse grande progresso, o que se tem ainda é que as guerras não foram excluídas totalmente do ordenamento jurídico internacional, ao passo que o que ocorreu foi a sua limitação. Nesse sentido, afirma Rezek:

O fato de ser hoje a guerra um ilícito internacional não deve fazer perder de vista que, até o começo do século em que vivemos, ela era uma opção perfeitamente legítima para que resolvessem pendências entre Estados. Por isso o direito internacional clássico abrigou amplo e pormenorizado estudo da guerra e da neutralidade. $\mathrm{O}$ quadro contemporâneo não mais justifica especial dispêndio de energias no exame de tudo quando compôs, outrora, o direito da guerra: parecem superadas sobretudo aquelas normas de protocolo militar e de natureza técnica que se compendiaram na Haia durante a virada do século. Mas não faria sentido ignorar que o fenômeno da guerra subsiste, e que o estudo de certas normas a ela inerentes não se converteu ainda, infelizmente, em arqueologia jurídica. (REZEK, 2000, p. $328)$.

Dentro deste novo cenário, a guerra como sendo um instrumento jurídico utilizado apenas em casos excepcionais veio a ser substituída pelos meios pacíficos de solução de conflitos, colocados em voga tanto no capítulo VI da Carta das Nações Unidas quanto no capítulo V da Carta da Organização dos Estados Americanos de 1948, os quais são 
subdivididos em meios diplomáticos, políticos, notadamente, conciliação, bons ofícios, mediação e diplomacia e em meios jurídicos, através do recurso a cortes internacionais e arbitragem (JUBILUT, 2007, p. 140), não existindo entre eles qualquer hierarquia.

Para além disso, se por um lado a comunidade internacional conseguiu progredir ao ponto de reconhecer a guerra como sendo um ilícito, de outro quadrante lamentavelmente conflitos com uma nova roupagem, por assim dizer, surgiram no cenário mundial.

\section{Conflitos internos x Conflitos Internacionalizados (híbridos ou mistos)}

Em um mundo em constante transformação, o direito não é capaz de acompanhar as rápidas mudanças sociais e tecnológicas da humanidade. É assim que, se por um lado ele alcança a regulamentação dos conflitos internacionais, por outro lado surgem de maneira desordenada e vultosa os denominados conflitos internos, os quais são definidos no artigo I do Protocolo II da Convenção de Genebra, como sendo aqueles:

[...]no território de uma Alta parte contratante entre as suas forças armadas e forças armadas dissidentes ou grupos armados organizados que, sob a direção de um comando responsável, exerçam sobre uma parte desse território um controle tal que lhes permita realizar operações militares contínuas e acordadas e aplicar o presente Protocolo.

$\mathrm{Na}$ atualidade, não é comum acontecer de dois Estados se enfrentarem declaradamente em um conflito armado. Lado outro, tem se tornado frequente a situação em que a guerra ocorra sem que lhe seja dado esse nome, ou na qual se opõem, no interior de um Estado, as autoridades estabelecidas e as suas forças armadas a uma parte da população (SWINARSKI, 1996, p. 27).

Pelo fato de terem se tornado frequentes, somado à ausência de uma regulamentação robusta e pelos seus efeitos devastadores, capazes de ferir de morte os direitos humanos das partes envolvidas, os conflitos armados clamam a atenção da comunidade internacional. Assim sendo, antes mesmo de serem definidos pelo Protocolo II de 1977, os legisladores da época já demonstravam preocupação com essa modalidade de conflito, inserindo no artigo $3^{\circ}$ da Convenção de Genebra de 1949, comum às quatro Convenções, a aplicabilidade do direito humanitário em uma situação de conflito armado interno, o qual mesmo de forma tímida, determinava que deveria ser respeitado dentro de um conflito doméstico o mínimo de humanidade, como menciona Rezek:

As quatro Convenções de 1949 dizem respeito ao conflito armado internacional. Contudo, um artigo vestibular (o art. $3^{\circ}$ ), comum a todas elas, fixa uma pauta mínima de humanidade a prevalecer mesmo nos conflitos internos, proibindo, por exemplo, 
a tortura, a tomada de reféns, o tratamento humilhante ou degradante, as condenações e execuções sem julgamento prévio. (REZEK, 2000, p. 366).

A partir de então, o Comitê Internacional da Cruz Vermelha (CICV), como sendo um organismo criado pela Convenção de Genebra de 1864 com o fim de proteger e dar assistência às vítimas de conflitos armados, passa a desempenhar suas funções no âmbito dos conflitos internos, uma vez que resta confirmado no segundo parágrafo do artigo $3^{\circ}$, que referida organização humanitária detém o direito de oferecer seus serviços em situações de conflitos armados não-internacionais.

O exercício deste "direito convencional de iniciativa" não pode ser considerado pelas Partes em conflito como incompatível com o princípio de não-intervenção nos assuntos internos do Estado, e nem poderá, sob esse pretexto, ser impossibilitada a sua aplicação. (SWINARSKI, 2000, p. 52).

Mesmo depois desse pequeno progresso no tocante a previsão normativa dos conflitos internos, o Direito Internacional ainda não é capaz de tutelá-los de maneira efetiva.

Precisamente desde 1945, entre os conflitos armados, têm os conflitos nãointernacionais sido muito mais frequentes em todo o mundo do que a guerra entre Estados. Esta situação, junto ao desenvolvimento de novos meios bélicos, originaram a necessidade de complementação da obra das Convenções de Genebra. (SWINARSKI, 2000, p. 20).

O que ocorre na realidade é a existência de uma proteção mitigada por parte da comunidade internacional, o que faz com que a violação de direitos humanos dos indivíduos residentes no Estado em conflito seja bastante elevada, haja vista que todas as barbaridades cometidas inclusive por entes organizados, que não o governo, não são vistas pelos olhos do mundo, por assim dizer.

E mesmo que o Direito Internacional Humanitário, através do II Protocolo às Convenções de Genebra tenha demonstrado sua preocupação com esta modalidade de conflitos buscando normatizá-los, as regras a ele inerentes não têm grande adesão, tornando sua efetividade praticamente inexistente (JUBILUT, 2007, p. 144).

No período compreendido entre a Paz de Vestefália e a Segunda Guerra Mundial, as leis internacionais relativas às guerras eram aplicadas tão somente aos conflitos travados entre Estados. No entanto, reconhecendo outro progresso, os conflitos internos são trazidos à tona no Estatuto de Roma, notadamente no inciso 2 do artigo $8^{\circ}$, o qual em suas alíneas "c" e "e" passa a regulamentar os crimes de guerra relativos à conflitos não-internacionais. As leis inerentes à guerra poderiam, via exceção, ser aplicadas às guerras civis apenas nos casos em que o Estado envolvido, ou um terceiro Estado, reconhecesse a beligerância da parte insurgente (AKANDE, 2012, p.1/2). 
Ocorre que, ainda que a beligerância tenha sido reconhecida em um conflito interno, isso não garantiria que o Direito Humanitário seria necessariamente aplicado no caso em concreto, surgindo daí uma incerteza quanto a esse pormenor, se fazendo cogente uma regulamentação mais precisa, como reiteradas vezes mencionado.

Faz-se necessário reconhecer que o Estatuto de Roma em um primeiro momento garantia uma proteção maior aos conflitos internacionais, o que veio a ser alterado em decorrência de uma emenda que ampliou de certa maneira sua tutela nos conflitos internos.

É assim que, após a entrada em vigor da emenda ao artigo $8^{\circ}$ do Estatuto de Roma, em 26/09/2012, a qual acrescentou novas condutas aos conflitos de índole não-internacional que antes eram exclusivas dos conflitos internacionais, a diferenciação na proteção legislativa entre esses dois conflitos foi diminuída consideravelmente. Porém, esta emenda é válida somente para os países que a ratificaram, estando este número atualmente em 34 (trinta e quatro) países ratificantes ${ }^{1}$.

Portanto, o que diferencia um conflito armado internacional de um não-internacional são as partes envolvidas no conflito. Os conflitos armados internacionais, em regra, são travados entre Estados, sendo que, na teoria, também podem ocorrer entre um Estado e um movimento nacional libertário. Porém, é muito difícil que um Estado admita, na prática, que esteja envolvido em uma guerra de libertação nacional, uma vez que isso implicaria na aceitação de que o mesmo é um regime racista, um ocupante estrangeiro ou um dominador colonial (SIVAKUMARAN, 2011, p.237).

Por outro lado, os conflitos armados internos são travados entre forças armadas governamentais e grupos armados não-estatais (facções rebeldes), ou entre grupos armados inimigos dentro de um Estado, sem que haja qualquer intervenção nas hostilidades por parte de algum Estado estrangeiro ou da ONU (VERHOEVEN, 2007, p.7).

$\mathrm{Na}$ atualidade, surge uma terceira espécie de conflito armado, o qual não se encaixa nas definições clássicas de conflitos armados internacionais e não-internacionais, sendo então intitulados "conflitos armados internacionalizados", que apresentam características tanto de um quanto de outro, formando uma espécie de conflito híbrido ou misto (CRAWFORD, 2008, p.20).

${ }^{1}$ Informação disponível no site: https://treaties.un.org/pages/ViewDetails.aspx?src=TREATY\&mtdsg_no=XVIII-10a\&chapter=18\&clang=_en. 
Sobre o tema, a Câmara de Apelações do Tribunal Penal Internacional para a exIugoslávia, em sua decisão datada de 15/07/1999 no caso DuskoTadic (Caso no IT-94-1), afirmou que:

É indiscutível que um conflito armado é internacional se o mesmo ocorre entre dois ou mais Estados. Ademais, no caso de um conflito armado interno se desencadear no território de um Estado, ele pode tornar-se internacional (ou, dependendo das circunstâncias, possuir caráter internacional ao lado de um conflito armado interno) se (i) outro Estado intervir naquele conflito através de suas tropas, ou alternativamente se (ii) alguns dos participantes no conflito armado interno agir em nome daquele outro Estado. ${ }^{2}$ (TPII, 1999, p.34, parágrafo 84).

Nesse mesmo sentido, Swinarski menciona que os conflitos que não são abertamente internacionais podem extravasar as fronteiras do território no qual se desenrolam por causa dos interesses políticos e das alianças que, mais uma vez, funcionam na comunidade internacional atual como um conflito interestatal-seja qual for o seu ponto de vista jurídico pode-se transformar em um assunto que rapidamente ultrapasse os próprios interesses das Partes em conflito. (SWINARSKI, 2000, p. 47)

Dentre várias situações hipotéticas que se encaixam em referido conceito, pode-se citar como exemplo a guerra travada entre forças governamentais de um determinado Estado e facções rebeldes ou grupos armados internos, com a intervenção ${ }^{3}$ de um ou mais Estados estrangeiros apoiando o governo, as facções rebeldes ou os grupos armados (VERHOEVEN, 2007, p.15).

\subsection{A importância da prática da distinção entre as espécies de conflitos armados para o Direito Humanitário}

É bastante comum que as partes envolvidas em um conflito, principalmente por questões políticas, apresentem resistência em classificar e assumir com transparência o conflito no qual estão envolvidas, sobretudo para evitar as consequências que isso possa ocasionar. Em razão disso é que as Convenções de Genebra não se limitam a serem aplicadas mediante a classificação jurídica que as partes atribuem a esse conflito, de modo que, mesmo que as partes venham a negar que estão vivenciando um conflito, o que vai definir ou não a aplicação das Convenções de Genebra e seus Protocolos é a realidade fática.

Para regular a guerra foi criado o Direito Internacional Humanitário, que pode assim ser definido:

\footnotetext{
2 Tradução nossa.

${ }^{3}$ Sobre as formas de intervenção de Estados estrangeiros em conflitos armados não-internacionais ver: SCHINDLER, Dietrich. International humanitarian law and internationalized internal armed conflicts;VITÉ, Sylvain. Typology of armed conflicts in international humanitarian law: legal concepts and actual situations.
} 
O direito internacional humanitário é o conjunto de normas internacionais, de origem convencional ou consuetudinária, especificamente destinado a ser aplicado nos conflitos armados, internacionais ou não-internacionais, e que limita, por razões humanitárias, o direito das Partes em conflito, de escolher livremente os métodos e os meios utilizados na guerra, ou que protege as pessoas e os bens afetados, ou que possam ser afetados pelo conflito. (SWINARSKI, 2000, p.18).

O processo de descolonização ocorrido no mundo todo trouxe consigo o surgimento de tensões ideológicas e políticas no seio dos Estados até então colonizados. Nasceu daí a necessidade de extensão da aplicabilidade do direito humanitário, antes restrito aos conflitos armados internacionais, aos conflitos internos, o que foi concretizado através dos Protocolos Adicionais às Convenções de Genebra.

A importância prática na distinção entre conflitos armados internacionais e nãointernacionais para o Direito Humanitário pode assim ser explicada:

O direito internacional humanitário tenta aliviar o sofrimento causado pela guerra e tenta proteger os fracos durante conflitos. Por isso, as quatro Convenções de Genebra de 1949e seus dois protocolos adicionais de 1977 estabelecem regras com o escopo de salvaguardar os feridos, doentes, náufragos, prisioneiros de guerra e civis o tanto quanto possível dos flagelos da guerra. Consequentemente, num primeiro momento, não parece ser relevante se o conflito é travado por vários Estados ou entre vários grupos armados dentro de um Estado. Entretanto, e infelizmente, isto é relevante. A proteção oferecida pelo direito internacional humanitário em relação a um conflito armado internacional ou Interestatal é muito mais ampla do que aquela oferecida a um conflito armado não-internacional ou um conflito armado dentro de um Estado, apesar do sofrimento ser o mesmo ou até mesmo mais severo num conflito armado interno. Como resultado, a natureza do conflito realmente faz diferença, e uma delimitação correta pode ser de vital importância para a proteção das pessoas contra a barbárie, que ainda se encontra frequentemente presente em conflitos armados. $^{4}$ (VERHOEVEN, 2007, p.3).

Nesse sentido, reconhecida a modalidade do conflito em ocorrência, o direito humanitário se valerá necessariamente daquilo que as normas de direito internacional o permitem operar e, como restou configurado anteriormente, em se tratando de um conflito armado internacional, a proteção e ferramentas a serem utilizadas pelo direito humanitário são bem mais amplas. Por outro lado, sendo o caso de um conflito interno, sua atuação se dará de forma limitada, menos abrangente, residindo aqui a importância de se distinguir as espécies de conflito em curso, sobretudo para se evitar que seja dispensada uma proteção menor do que aquela que a norma garante.

\section{$4 O$ contexto histórico do conflito no Sudão do Sul}

\footnotetext{
${ }^{4}$ Tradução nossa.
} 
O Sudão do Sul é o mais novo Estado-Nação do mundo. Embora o país tenha experimentado um período de paz relativa pós-emancipação entre 2011 e 2013, um conflito foi iniciado envolvendo os principais grupos étnicos. A guerra civil conduziu o Sudão do Sul a um caos humanitário, sendo que metade de sua população depende de ajuda humanitária.

Em dezembro de 2013, a guerra civil teve início no Sudão do Sul. O presidente Salva Kiir, da etnia Dinka, acusou seu antigo vice-presidente Riek Machar, da etnia Nuer, de tentar derrubá-lo do poder por meio de um golpe de Estado. A disputa tomou conta de Juba e se espalhou além da capital do país. Nesse contexto, é questionável o papel dos grupos étnicos como causa do conflito, já que metade dos políticos presos pelo governo por supostamente planejar o movimento são de origem Dinka, semelhantemente ao presidente da nação. Além disso, a disputa pelo controle da região rica em petróleo ao norte do Sudão do Sul aparentemente contribuiu de forma significativa para o início das hostilidades. Entretanto, apesar da pequena influência dos grupos étnicos no estopim do conflito, a violência tornou-se gradativamente étnica, colocando Dinkas contra Nuers (RADON e LOGAN, 2014, p. 150).

Uma vez iniciada a guerra civil, repetidas tentativas de se alcançar um acordo de paz entre Salva Kiir e Riek Machar falharam. Entre os atores internacionais, a Autoridade Intergovernamental para o Desenvolvimento (IGAD), bloco comercial que reúne oito países da África Oriental, teve um papel proeminente na facilitação do diálogo entre os dois principais contendores. A Etiópia, em particular, sediou importantes encontros com a intenção de estabilizar a região. Enquanto o conflito continua, a situação humanitária no Sudão do Sul deteriora rapidamente. Em 2014, já existiam 1,5 milhões de deslocados internos no Sudão do Sul. Deste total, mais de 90.000 pessoas buscaram refúgio em degradados campos de deslocados internos dentro das bases da Organização das Nações Unidas (ONU). Ademais, ao menos cinco milhões de pessoas necessitavam urgentemente de assistência humanitária no país. Nesse contexto, a fome aguda merece atenção especial, já que a guerra impede que os sul-sudaneses cultivem suas plantações (RADON e LOGAN, 2014, p. 163).

Hanzich (2011, p. 38) analisa a história completa do Sudão, desde o momento no qual o país se transformou em uma entidade política em 1821 até a independência do Sudão do Sul em 2011. Ele explica que o país começou a participar da geopolítica mundial por volta de 1880, quando Muhammad Ahmad, alegando ser um profeta, uniu as diversas tribos através da jihad islâmica e obteve o controle de todo o Sudão. Ele morreu logo após a conquista de Cartum em 1885, o que lançou o país em sua primeira sequência de guerras civis. Tirando proveito da caótica situação sudanesa, a Grã-Bretanha e o Egito juntaram forças para tomar o 
controle do Sudão em 1898. Entre os anos de 1899 e 1956, o país esteve submisso ao colonialismo anglo-egípcio, o que prejudicou seu sistema político, social e o desenvolvimento econômico. Em 1 de janeiro de 1956, o Sudão tornou-se um Estado independente.

Hanzich afirma que após quatro anos de independência, o Sudão já havia sido capaz de multiplicar sua receita interna e de equilibrar seu orçamento. Todavia, o investimento ficou restrito à região de Cartum e às cidades na direção do Mar Vermelho. Assim, Darfur e a região sul do país foram negligenciados. Hanzich também frisa que a religião e as diferenças étnicas entre os muçulmanos árabes do Norte e os cristãos animistas do Sul exacerbaram as políticas discriminatórias de Cartum sobre Darfur e o atual Sudão do Sul.

Em 1989, depois de um golpe militar, o presidente Omar Al-Bashir iniciou um processo de solidificação do islamismo árabe, conhecido como "sudanização" do país, por meio da Lei da Sharia, direcionando seus esforços militares contra os "não-crentes" do Sul. Entretanto, com o objetivo de manter apoio e postergar envolvimento internacional, Bashir consentiu em assinar o Acordo de Paz Compreensivo (CPA) em janeiro de 2005, o qual encerrou a Segunda Guerra Civil Sudanesa e resultou na independência do Sudão do Sul em 2011. Hanzich finalmente destaca o fato de que, no período entre 2005 e 2011, a renda proveniente do petróleo foi dividida igualmente entre o Sudão e a região autônoma que atualmente corresponde ao Sudão do Sul, mesmo que a grande maioria dele fosse produzida no sul do país (HANZICH, 2011, p. 40).

\subsection{A tipificação do conflito sul-sudanês.}

Para que um conflito seja considerado interno, há que ser preenchidos todos os requisitos exigidos pelo artigo I do Protocolo II da Convenção de Genebra, notadamente, a) realizado no território de um Estado; b) existência de pelo menos duas partes identificadas organizadas (forças governamentais e oposição) que se enfrentam; c) existência de um responsável que tenha comando militar ou político.

Diferente disso, o cenário do Sudão do Sul é significativamente influenciado por atores estrangeiros. Por exemplo, o desejo queniano de obter mais poder e se posicionar como principal força regional tem contribuído para seu engajamento no país. Bachman (2014, p. 132) afirma que o Quênia espera obter um substantivo crescimento econômico caso o Sudão do Sul se fortaleça. Por essa razão, as companhias quenianas são os maiores investidores no Estado vizinho, especialmente nas áreas bancária, de construção, de infraestrutura, de transporte aéreo e do incipiente setor comercial. Além das atividades econômicas citadas, o 
principal interesse do Quênia no Sudão do Sul é construir um oleoduto de Juba até uma refinaria no arquipélago queniano de Lamu, impulsionando o desenvolvimento econômico na normalmente negligenciada região norte do país.

Além disso, desde 8 de julho de 2011, a ONU estabeleceu a Missão das Nações Unidas no Sudão do Sul (UNMISS) para consolidar a paz e segurança, ajudando a fomentar o desenvolvimento no novo país. Porém, desde o início das hostilidades em 2013, o foco principal da missão da ONU passou a ser a proteção de civis e dos direitos humanos, bem como a criação das condições de segurança necessárias para a realização de ajuda humanitária nas áreas mais afetadas pelo conflito (UNITED NATIONS, 2015).

A guerra civil no Sudão do Sul possui ainda o engajamento efetivo das organizações regionais buscando a resolução do conflito. Como forma de atingir esse objetivo, Kerr de Oliveira e Silva (2011, p. 28) argumentam que o IGAD e a União Africana (UA) deveriam desenvolver programas de cooperação que ajudariam o governo sul-sudanês a gastar sua receita de forma eficiente, focando na integração da economia nacional, bem como na construção de infraestrutura de transporte, energia e comunicações. As organizações regionais também deveriam pressionar o governo do país a prover serviços básicos para a população como segurança pública, saúde, educação e alimentação. Logo, Kerr de Oliveira e Silva defendem que uma alternativa sustentável para a resolução de conflitos na área do IGAD é a integração regional baseada na construção de infraestrutura (KERR DE OLIVEIRA e SILVA, 2011, p. 31).

Lyman (2013, p. 338) também enfatiza a importância das organizações regionais para o processo de paz sul-sudanês. Ele salienta o papel fundamental que a UA tem realizado no conflito em Darfur e os esforços da organização para estabelecer regimes democráticos em todo o continente africano. Assim, a legitimidade e a expertise das organizações regionais têm papel importante no processo de paz do Sudão do Sul, contribuindo também para que a possibilidade de um conflito puramente interno seja descartada. Dessa forma, apesar de travado dentro do território nacional, o conflito sul-sudanês pode ser configurado como internacionalizado, híbrido ou misto.

\subsection{As principais causas do conflito sul-sudanês}

Radon e Logan examinam o Sudão do Sul desde sua independência em 2011, além dos fatores que conduziram o novo país à violeta guerra civil. De acordo com os autores, alguns desses fatores são: a falta de nacionalismo, uma vez que os sul-sudaneses possuem 
laços de lealdade mais fortes com seus líderes tribais e milícias locais do que com sua nação; a concentração de poder no governo, o qual se recusa a descentralizar autonomia e recursos; sistema de governo presidencial; e a fragilidade das instituições sul-sudanesas, as quais estão subordinadas aos interesses de grupos locais.

Entretanto, Radon e Logan (2014, p. 151) enfatizam que, para examinar todos os fatores acima descritos, devem ser levadas em consideração a excessiva dependência do país em receitas provenientes do petróleo e suas implicações nos campos político, econômico e social. Os autores explicam que o Sudão do Sul é o país mais dependente de petróleo do planeta, sendo que esse produto representa cerca de $98 \%$ de suas exportações. Ademais, $80 \%$ do produto interno bruto (PIB) do Estado consiste do comércio desse mineral.

A alta dependência deixa o Sudão do Sul extremamente vulnerável aos fatores que afetam a produção de petróleo no país, assim como ao mercado internacional do produto. Radon e Logan (2014, p. 160) criticam o governo local, afirmando que essa dependência está intimamente relacionada a má governança. Os autores explicam que o governo é ineficiente porque ele continua a receber toda a receita da produção da commodity independentemente da forma como administra sua população. Radon e Logan atribuem ainda a deflagração do conflito sul-sudanês em 2013 à paralisação da produção de petróleo no ano anterior, devido a uma disputa entre Juba e Cartum sobre a receita do produto. Sem a produção de petróleo, o governo corrupto de Juba simplesmente não foi capaz de comprar a lealdade dos líderes locais, resultando na guerra civil que se estende até os dias atuais (RADON e LOGAN, 2014, p. 161).

Kerr de Oliveira e Silva concordam com Radon e Logan no que diz respeito ao modo como a dependência econômica em petróleo afeta a política sul-sudanesa. Eles destacam a relação desequilibrada entre o novo país e o Sudão, que conduz por meio de oleodutos o petróleo do Sudão do Sul até o Mar Vermelho. Kerr de Oliveira e Silva (2011, p. 25) também frisam o fato de que aproximadamente $90 \%$ da população sul-sudanesa vive com menos de um dólar por dia, estando abaixo da linha de extrema pobreza. Somente 10\% das casas do país possuem algum acesso à eletricidade (mesmo que somente por algumas horas ao dia) e menos de 5\% têm acesso a gás de cozinha. Além disso, 92,6\% da população ainda utiliza combustíveis sólidos para cozinhar (lenha, carvão, biomassa ou estrume), ocasionando uma alta incidência de doenças respiratórias.

Finalmente, Radon e Logan (2014, p. 163) afirmam que o Sudão do Sul necessita diversificar sua economia por meio de investimento em setores não-extrativistas, assim como 
canalizar a receita do petróleo para a geração de mais igualdade e melhoria das condições de vida da população em geral. Ainda segundo os autores, uma solução de longo prazo para o conflito do Sudão do Sul é a redução de sua dependência em petróleo. Portanto, a comunidade internacional, provavelmente através da estrutura existente da UNMISS, precisa colocar a receita do petróleo fora do alcance do governo sul-sudanês, o qual teria que se comprometer a realizar reformas estruturais e descentralizar poder para receber sua cota.

Dessa maneira, a literatura existente aborda as causas e a escalada do conflito no Sudão do Sul. Muito embora diversos fatores internos certamente contribuíram para a guerra civil como a tensão étnica, a má governança e as péssimas condições sociais, o fator econômico tem sido decisivo. Existe também um consenso entre os autores de que os atores internacionais, normalmente buscando benefícios econômicos, afetam significativamente a política sul-sudanesa.

\section{Conclusões}

Pelo presente estudo, é possível verificar que a comunidade internacional tem um papel decisivo na pacificação do Sudão do Sul, o qual pode ser classificado como conflito internacionalizado, híbrido ou misto. Nesse contexto, pode-se concluir que o sistema de mercado internacional afeta significativamente o conflito no Sudão do Sul. Apesar de possuir um caráter étnico, a Guerra Civil Sul-Sudanesa está mais diretamente relacionada à dependência que o país mantém da receita do petróleo, o que constitui a principal causa do conflito. A disputa pela produção do mineral e sua renda tem resultado em um conflito étnico que levou o Sudão do Sul a uma terrível crise humanitária.

O governo sul-sudanês tem usado a receita do petróleo para se manter no poder à frente do país sem levar em conta as necessidades de sua própria população. As elites leais ao governo concentram a maioria dos recursos nacionais, o que contribui para a deterioração da situação humanitária que é caótica em muitas partes do Sudão do Sul. Atualmente, milhões de pessoas necessitam de assistência humanitária, enquanto a elite que conduz o país beneficia-se do comércio da commodity.

Nessa conjuntura, a redução da dependência do Sudão do Sul em petróleo pode ser alcançada por meio da descentralização de poder. O fortalecimento de governos locais permitiria uma distribuição mais justa dos recursos e a diversificação da economia, melhorando as condições de vida da população e reduzindo o conflito no país. Por essa razão, o engajamento da comunidade internacional, através de organizações internacionais, é 
primordial para que sejam impostas ao governo nacional reformas estruturais e descentralização de poder.

Esse estudo não esgota todo o conhecimento sobre o conflito sul-sudanês. Embora esse artigo recomende a imposição de reformas estruturais e a descentralização de poder no Sudão do Sul, é questionável se as organizações internacionais, em especial a ONU por meio da UNMISS, possuem os meios necessários para impor tais mudanças. Dessa forma, este trabalho seria eficientemente complementado por outros estudos relacionados ao papel e capacidades da UNMISS, bem como sua efetividade como operação de paz.

\section{Referências}

AKANDE, Dapo. Classification of Armed Conflicts: Relevant Legal Concepts. In: WILMSHURST, Elizabeth (org.). International Law and the Classification of Conflicts. Oxford: University of Oxford, 2012.

ARENDT, Hannah. Origens do totalitarismo: antissemitismo, imperialismo, totalitarismo. Tradução: Roberto Raposo. São Paulo: Campanha das Letras, 2012.

BARTELS, Rogier. Timelines, borderlines and conflicts. The historical evolution of the legal divide between international and non-international armed conflicts. In: International Review of the Red Cross. Genebra: Comitê Internacional da Cruz Vermelha. v. 91, n. 873 , p. $35-67,2009$.

BACHMAN, J. Kenya and International Security: Enabling Globalization, Stabilizing 'Stateness', and Deploying Enforcement. Globalizations. v. 9, n. 1, p. 125-143, 2012. https://www.researchgate.net/publication/254290757_Kenya_and_ 
International_Security_Enabling_Globalisation_Stabilising_'Stateness'_and_Deployi ng_Enforcement. Acesso em: 8 agosto 2018.

BOBBIO, Norberto. O problema da guerra e as vias da paz. Trad. Álvaro Lorencini. São Paulo: Editora Unesp, 2003.

CRAWFORD, Emily. Unequal before the law: Questioning the distinction between types of armed conflict in international law. Tese submetida à Faculdade de Direito da Universidade de New South Wales, como requisito para a obtenção do título de Doutor em Filosofia. Sydney: University of New South Wales, 2008.

HANZICH, R. Struggles in South Sudan. Harvard International Review. v. 33, n. 1, p. 3841, 2011. Disponível em: https://www.researchgate.net/publication/292284961 _Struggles_in_south_Sudan. Acesso em 1 agosto 2018.

JUBILUT, Liliana Lyra. O direito internacional dos refugiados e sua aplicação no ordenamento jurídico brasileiro. São Paulo: Método, 2007.

KANT, Immanuel. A paz perpétua. Trad. Marco Zingano. Porto Alegre: L\&PM Editores, 2017.

KELSEN, Hans. A paz pelo direito. Trad. Lenita Ananias do Nascimento. São Paulo: Editora WMF Martins Fontes, 2010.

KERR DE OLIVEIRA, L; SILVA, I. C. Sudão do Sul: Novo País, Enormes Desafios. Meridiano 47 - Boletim de Análise de Conjuntura em Relações Internacionais. v. 12 n. 128, p. 24-33, 2011. Disponível em: https://www.researchgate.net /publication/279647431_Sudao_do_Sul_novo_pais_enormes_desafios. Acesso em: 25 setembro 2018.

LIGA DAS NAÇÕES. Pacto da Liga das Nações de 1920. Disponível em: http://pfdc.pgr.mpf.mp.br/atuacao-e-conteudos-deapoio/legislacao/segurancapublica/ PACTO_DA_SOCIEDADE_DAS_NACOES.pdf. Acesso em: 7 janeiro 2018.

LITONJUA, M. D. Third World/Global South: From Modernization, to Dependent/Liberation, to Post development. Journal of Third World Studies. v. 29, n. $1, \quad$ p. 25-56, 2012. Disponível em: https://www.researchgate.net/publication/288622087_Third _worldglobal_south_From_modernization_to_dependencyliberation_to_postdevelop ment. Acesso em: 25 setembro 2018.

LYMAN, P. N. Sudan-South Sudan: The Unfinished Tasks. American Foreign Policy Interests. v. 35, n. 6, p. 333-338, 2013. Disponível em: https://www.researchgate.net/publication/263568949_Sudan-South_Sudan_The_ Unfinished_Tasks. Acesso em: 30 março 2018.

MAZZUOLI, Valerio de Oliveira (2016). Curso de direito internacional público. $10^{\text {a }}$ edição. São Paulo: Revista dos Tribunais, 2016. 
ORDEMATT, Jed. Between Law and Reality: 'New Wars' and Internationalised Armed Conflict. In: Amsterdam Law Forum. Amsterdam: VU University Amsterdam, 2013, v. 5.

ORGANIZAÇÃO DAS NAÇÕES UNIDAS (ONU) (1998). Estatuto de Roma. Disponível em: https://www.planalto.gov.br/ccivil_03/decreto/2002/d4388.htm. Acesso em: 15 janeiro 2018.

RADON, J; LOGAN, S. South Sudan: Governance Arrangements, War, and Peace. Journal of International Affairs. v. 68, n. 1, p. 149-167, 2014.

REZEK, J. F. Direito Internacional Público: curso elementar. 8. ed. São Paulo: Saraiva, 2000.

SIVAKUMARAN, Sandesh. Re-envisaging the International Law of Internal Armed Conflict. In: The European Journal of International Law. Oxford: Oxford University Press, 2011.

SWINARSKI, C. Introdução ao direito internacional humanitário. Brasília: Comitê Internacional da Cruz Vermelha e Instituto Interamericano de Direitos Humanos, 1996.

UNITED NATIONS. United Nations Mission in South Sudan. 2015. Disponível em: http://www.un.org/en/peacekeeping/missions/unmiss/. Acesso em: 13 setembro 2015.

VERHOEVEN, Sten. International and Non-international Armed Conflicts. In: VERHOEVEN, Sten; WOUTERS, Jan (orgs.). Armed Conflicts and the Law. Lovaina: Institute for International Law, 2007, n.107.

WILLMOTT, Deidre. Removing the Distinction between International and Non-International Armed Conflict in the Rome Statute of the International Criminal Court. In: Melbourne Journal of International Law. Melbourne: The University of Melbourne, 2004, v.5. 